whole group with pSS ( $\mathrm{p}<0.001$ ), while for the Ro and/or La positive group was 47.1. Ten years survivorship in pSS patients was not significantly lower with respect to the general population (86.5 vs $90 \%$ ) calculated with the aid of life tables of the Italian general population (matched for age and sex).

Conclusion Patients with purpura, parotid swelling, low C4 levels and cryoglobulinemia present an increased risk to develop lymphoproliferative disorders. These clinical and laboratory findings seem to identify a subgroup of patients with pSS which should be controlled and, maybe, treated in a different way.

\section{FRI0225 GLUCOCORTICOSTEROID AND CYTOTOXIC THERAPY}

VI Vasiliev, MV Simonova, TN Safonova, NS Shornikova. Department of Rheumatology, Institute of Rheumatology of RAMS, Moscow, Russia

10.1136/annrheumdis-2001.318

\section{Background}

Objectives To assess the effect of long-term glucocorticosteroid (GCS) low doses and cytostatics taking on clinical-laboratory SS manifestations.

Methods 500 SS pts divided into 4 groups were included into the study. 1st group - 200 of SS pts had $5 \mathrm{mg}$ of Prednisolone daily, 1.8 for a year, $0.9-1.8$ for subsequent years and chlorobutin $-2 \mathrm{mg}$ daily for a year, 360-720 mg for the next 5-15 years. 2nd group - 100 SS pts had Prednisolone according the same scheme and cyclophosphane $200 \mathrm{mg}$ twice a month, $4.8 \mathrm{mg}$ for a year, 2.4-4.8 g for the next 5-15 years. $3 \mathrm{~d}$ group - $100 \mathrm{SS}$ pts had Prednisolone according the same scheme for 5-15 years. 4th group - 100 SS pts had only substitution therapy. Reliable improvement of stomatological (decrease of salivary glands, disappearing or decrease of frequency of parotitis, increase of salivation), ophthalmologic (residing of cornea dystrophy) and some systemic manifestations disappearing of artralgia, regional lymphadenopathy, decrease of morning stiffness) were noticed only in the fist three groups of pts and in the 1st and 2nd groups it was more pronounced $(<0.001)$. Only in the 1 st and 2 nd groups disappearing of purpura relapse in the third of pts. ESR, fibrinogens levels, general protein, G-globulins, 3 classes of immunoglobulins, CIC and RF titers decrease in 5 years was found only in the 1 st and 2 nd groups of pts $(p<0.001)$. Substantial improvement (1st, 2nd groups - 30\%, 3d - 10\%) and moderate improvement (1st, 2nd groups - 25\%, 3d - 20\%) was found only in pts with cytostatics and GCS therapy. 30\% (1st and 2nd groups) and $40 \%$ (3d group) pts needed more potent therapy, whereas $60 \%$ (4th) of pts had therapy due to development of different stage of severity of systemic manifestations.

Results

Conclusion Obtained data demonstrate the necessity of low doses of GCS and chlorobutin/cyclophosphane in early terms of SS with glandular manifestations. In some cases such therapy is effective during systemic manifestations of the disease which is not dangerous for the life of patient.

\section{FRI0226 EFECT OF LOW DOSES OF PREDNISOLONE ON BONE MINERAL DENSITY (BMD) IN SJOGREN'S SYNDROME}

NS Shornikova, VI Vasiliev, AV Smirnov. Department of Rheumatology, Institute of Rheumatology of RAMS, Moscow, Russia
Background Lately the effect of corticosteroids on BMD during different diseases including autoimmunic ones was widely discussed.

Objectives To determine the effect of long-term ( $>5$ years) taking of Prednisolone in daily dosage of $2-2.5 \mathrm{mg}$ on BMD in pts with Sjogren's syndrome (SS).

Methods 112 female pts aged 33-73 with reliable SS diagnosis were examined. $56(50 \%)$ out of them were treated for more then 5 years by low doses of hormones. As it was evident that menopausal beginning influenced BMD, all examined persons were divided into 4 groups: pts with retained menstrual cycle who did not receive hormones (1st group - 32pts with median age $40.7(7.8$ years $)$ and those who for a long time took low doses ( $<5 \mathrm{mg} /$ day) of Prednisolone (2nd group - 24 pts with median age 41.5(4.7 years); women of postmenopausal period who were never treated by hormones ( $3 \mathrm{~d}$ group -24 pts aged 57.5(6.7 year, postmenopausal period 7.3(0.8 years) and those who for a long time took low doses of Prednisolone (4th group - 32 pts aged 52.3(5.6 years; postmenopausal period 8.1(0.7 years). All groups of pts were comparable by weight and height coefficient. Assessment of BMD in lumbar area of the spine (L1L4) and left femoral neck was carried out by double X-ray absorptiometry on densitometer QDR-1000 («Hologic», USA). Statistical analysis was done by Student's t-criterion and (2 criterion).

Results BMD in L1-L4 was correspondingly to 1-4 groups: $1.030\left(0.128 \mathrm{~g} / \mathrm{cm}^{2}, 0.983\left(0.100 \mathrm{~g} / \mathrm{cm}^{2}, 0.858\left(0.123 \mathrm{~g} / \mathrm{cm}^{2}\right.\right.\right.$ and $0.837\left(0.124 \mathrm{~g} / \mathrm{cm}^{2}\right.$, there were no reliable difference in comparison of 1 st and 2 nd, $3 \mathrm{~d}$ and 4 th groups. BMD in femoral neck was as follows according to groups: $0.891\left(0.115 \mathrm{~g} / \mathrm{cm}^{2}, 0.815\right.$ $\left(0.104 \mathrm{~g} / \mathrm{cm}^{2}, 0.740\left(0.116 \mathrm{~g} / \mathrm{cm}^{2}\right.\right.$ and $0.763\left(0.090 \mathrm{~g} / \mathrm{cm}^{2}\right.$. During analysis it turned out that BMD in femoral neck in the 2 nd group was reliably lower than in the 1 st group $(t=2.59, \mathrm{p}<$ 0.01 ), during comparison of the $3 \mathrm{~d}$ and 4th group there were no differences. In the 1 st and 2 nd groups there was no osteoporosis $(\mathrm{T}<2.5 \mathrm{SD})$, osteopenia $(\mathrm{T}<1.0 \mathrm{SD})$ in L1-L4 and in neck developed correspondingly in $25 \%$ and $18.75 \%$ of cases in the1st group and in $33.3 \%$ and $41.7 \%$ in the 2 nd group. In the $3 \mathrm{~d}$ and 4th groups osteoporosis and osteopenia developed mainly with equal frequency in corresponding areas.

Conclusion In women with retained menstrual cycle the longterm taking of low doses of Prednisolone results in BMD decrease in femoral neck, frequency of osteopenia grows but osteoporosis in this case does not develop. In postmenopausal period taking of low doses of hormones has no substantial effect on the frequency of osteoporosis and osteopenia development.

\section{FRI0227 MONOCLONAL SECRETION DUIRING SJOGREN'S SYNDROME (SS)}

EY Varlamova, VI Vasiliev, EY Saridi, MV Simonova, NS Shornikova, VR Gorodetsky, NN Tupizyn, EN Sholokhova. Department of Rheumatology, Institute of Rheumatology of RAMS, Moscow, Russia

\subsection{6/annrheumdis-2001.320}

Background Finding of monoclonal immunoglobulins and light chains in serum and urine of SS pts suggests the possibility of SS transformation into malignant lympho-proliferative diseases.

Objectives To characterise the spectrum of monoclonal secretion in SS, to evaluate the role of monoclonal immunoglobulinopathy in the development of I-secreting lymphomas in SS.

Methods 24 females aged 25-75 years (49.2(3.4) with SS duration of 2-28 years admitted into Institute of Rheumatology 
during 2000 had typing of monoclonal immunoglobulins or their fragments with the help of: I - serum agarosa gel and concentrated urine electrophoresis with subsequent densitometry of electrophoregraphs, 2 - immunofixation and immunoelectrophoresis with monospesific anti-serums ã, á, ì, å, ä, ê, ë.

Results IgMk-3, IgAk-2 monoclonal immunoglobulins were found in 5 pts $(25 \%)$ in blood serum, Bens-Johns protein (BJk) was found in urine of $3 \mathrm{pts}$ and IgMk in one patient. Thorough examination of pts with monoclonal secretion with carrying out of immunophenotyping of bioptates on lymphatic nodes and small salivary glands on lower lip enabled us to diagnose big cell lymphoma (2-ptorein BJk in the urine, IgMk in serum in 4 pts and plasmacytoma (IgGk) in one patient. It was not possible to confirm the presence of malignant lymphatic proliferation in this study in pts with IgAk (2), IgMk (1) monoclonal secretion in serum and vestige protein secretion BJk in the urine.

Conclusion Revealing of monoclonal immunoglobulins and light chains of immunoglobulins enables us to suggest the appearing of malignant lymphatic proliferation in SS pts and during further immunophenotyping of lymphatic nodes to diagnose the development of immunosecreting lymphomas in the half $(55 \%)$ of pts.

\section{FRI0228 ECHOCARDIOGRAPHIC FINDINGS IN PATIENTS WITH PRIMARY SJOGREN'S SYNDROME}

VA Vassiliou, I Moyssakis, KA Boki, MK Kyriakidis, HM Moutsopoulos. Department of Pathophysiology, National University of Athens School of Medicine, Athens, Greece

\subsection{6/annrheumdis-2001.321}

Background Cardiac involvement and clinically silent cardiac changes are reported rarely in patients with primary Sjogren's Syndrome (pSS) whereas: a. increased rate of pericarditis (usually silent with echocardiographic findings) and mitral valve regurgitation, b. myocardiac involvement (autoimmune - asymptomatic myocarditis), and c. left ventricular diastolic dysfunction have been presented in case reports and controlled studies.

Objectives The echocardiographic evaluation of the anatomic and functional heart disorders in patients with pSS (without risk factors for coronary heart disease or other symptoms of heart disease), the comparison of these findings with that of the control group, and the correlation with clinical and laboratory data (ANA, anti-Ro (SSA), anti-La (SSB), anti-CL, anti-b2GPI, RF).

Methods Pulsed, colour Doppler echocardiography was performed in seventy eight (78) patients (pts) with pSS (european criteria) (75 women and 3 men), mean age $51 \pm 11.6$ (years) and mean disease duration $7.7 \pm 4.26$ (years) and 80 healthy controls (78 women and 2 men) mean age $51 \pm 9.5$ (years). Left-ventricular (LV) dimensions and interventricular septum and posterior wall thickness at end-diastole were measured for the calculation of the fractional shortening (FS) and left ventricular mass with the Penn convention formula. Measurements of left ventricular mass were divided by body surface area to obtain left ventricular mass index (LVmass index). We also evaluated parameters of RV and LV diastolic function including early and late atrioventricular (AV) flow velocities ( $\mathrm{E}$ and $\mathrm{A}$ wave respectively), $\mathrm{E} / \mathrm{A}$ ratio, deceleration time (DT) and isovolumic relaxation time (IVRT). Pulmonary artery systolic pressure (PASP) was estimated by the peak regurgitation velocity from the tricuspid valve plus the estimated right atrial pressure, while valve lessions by continuous and colour Doppler.
Results Twenty-three (29.5\%) pts had mild mitral valve regurgitation versus 7 controls $(p<0.01), 6$ pts had mild tricuspid regurgitation $(\mathrm{p}<0.05)$ and $14(18 \%)$ pts had mild aortic valve regurgitation. Pericardial effusion was found in 3 pts whereas fourteen $(18 \%)$ pts had pulmonary hypertension (PASP >35 $\mathrm{mmHg})(\mathrm{p}<0.001)$. Mitral valve regurgitation was significantly associated with the presence of the anti-La antibodies $(\mathrm{p}<0.05)$ and pulmonary hypertension with lung disease (carbon monoxide diffusing capacity ${ }^{-2}$ vs $\left.84.71 \pm 15.36 \mathrm{gm}^{-2}, \mathrm{p}<0.001\right)$ and was correlated with the presence of purpura $(P=0.02)$, lung disease $(\mathrm{p}<0.001)$ and the presence of rheumatoid factor $(\mathrm{P}=$ 0.02).

Conclusion Patients with pSS and no clinically apparent heart disease had, more often than healthy controls, mild mitral and tricuspid valve regurgitation, pulmonary hypertension, and had increased left ventricular mass index. The LV mass index is correlated with purpura, lung disease and the presence of rheumatoid factor.

\section{FRI0229 HLA ANTIGENS' FREQUENCIES IN SPANISH PATIENTS WITH PRIMARY SJÖGREN SYNDROME}

C Fernández-Carballido, JJ Alegre-Sancho, JA Román-Ivorra, S Fernández, L Abad, N Puig. Sección de Reumatología, Hospital Universitario Dr. Peset, Valencia, Spain

\subsection{6/annrheumdis-2001.322}

Background There are few data about HLA antigens' frequencies in Spanish patients with Primary Sjögren Syndrome (PSS).

Objectives To evaluate HLA antigens' prevalence in patients with PSS and compare these frequencies with a control population.

Methods 113 patients with PSS from a Mediterranean city (Valencia, Spain) were consecutively selected. All patients fulfilled 4 or more EEC criteria; 82 fulfilled modified-EEC criteria. HLA serologic typing was carried out and the frequencies obtained in PSS patients were compared with the control population's frequencies (236 healthy blood donnors from the same city).

Results The antigens' prevalences of PSS patients significatively different from the control group were:

\begin{tabular}{|c|c|c|c|c|c|c|}
\hline & B21 & DR1 & DR2 & DR3 & DR4 & DR7 \\
\hline $\begin{array}{l}\text { All } \\
\text { patients ( } n \\
=113 \text { ) }\end{array}$ & $\begin{array}{l}\mathrm{OR}=0.36 \\
(0.18- \\
0.74) ; \mathrm{P}= \\
0.002\end{array}$ & $\begin{array}{l}\mathrm{OR}=0,4 \\
(0.23- \\
0.94) ; p= \\
0,022\end{array}$ & $\begin{array}{l}\mathrm{OR}=1.93 \\
(1.08- \\
3.46) ; \mathrm{p}= \\
0.017\end{array}$ & $\begin{array}{l}\mathrm{OR}=1.98 \\
(1.05- \\
3.02) ; p= \\
0.03\end{array}$ & $\begin{array}{l}\mathrm{OR}=2.09 \\
(1.16- \\
3.74) ; p= \\
0.007\end{array}$ & $\begin{array}{l}\mathrm{OR}=0.51 \\
(0.28- \\
0.90) ; p= \\
0.013\end{array}$ \\
\hline $\begin{array}{l}\text { Modified- } \\
\text { EEC } \\
\text { criteria } \\
\text { only ( } n= \\
82 \text { ) }\end{array}$ & $\begin{array}{l}\text { No } \\
\text { significance }\end{array}$ & $\begin{array}{l}\text { No } \\
\text { significance }\end{array}$ & $\begin{array}{l}\mathrm{OR}=2.13 \\
(1.17- \\
3.89) ; \mathrm{p}= \\
0.014\end{array}$ & $\begin{array}{l}\mathrm{OR}=2.02 \\
(1.16- \\
3.50) ; p= \\
0.018\end{array}$ & $\begin{array}{l}\mathrm{OR}=2.34 \\
(1.29- \\
4.27) ; \mathrm{p}= \\
0.008\end{array}$ & $\begin{array}{l}\mathrm{OR}=0.47 \\
(0.25- \\
0.88) ; p= \\
0.019\end{array}$ \\
\hline
\end{tabular}

Conclusion Some HLA antigens in our PSS patients are different from those described in other Mediterranean areas. In our population HLA DR2, DR3 and DR4 are associated with PSS; without differences in DR5 frequencies (Greek population). Moreover, HLA DR7 acts as a protective factor for this disease. 